\title{
DNA Binding and Topoisomerase II Inhibitory Activity of Water-Soluble Ruthenium(II) and Rhodium(III) Complexes
}

Sanjay Kumar Singh, $†$ Shweta Joshi, $\neq$ Alok Ranjan Singh,, Jitendra Kumar Saxena ${ }^{2}$ and Daya Shankar Pandey ${ }^{\star, \dagger}$

${ }^{\dagger}$ Department of Chemistry, Faculty of Science, Banaras Hindu University, Varanasi -221 005 (U.P.), India

‡Division of Biochemistry, Central Drug Research Institute, Chattar Manzil P.O. Box 173, Lucknow-226 001 (U.P.), India

\section{Supporting Information}

Control experiments of the complexes with DNA (with/without topoisomerase II): The pBR322 Supercoiled DNA was incubated with the compounds at two concentrations i.e. 10 $\mu \mathrm{g} /$ reaction mixture Figure S1, S2 and $1 \mu \mathrm{g} /$ reaction mixture Figure S3, S4. At $10 \mu \mathrm{g} /$ reaction mixture concentration no complex formation was observed by complexes $1,3 \boldsymbol{c}, \mathbf{3 d}, \mathbf{4}, \mathbf{5}, \mathbf{5 a}$ and DNA migrated as supercoiled DNA. While complexes $2,3, \mathbf{1 a}, \mathbf{2 a}, \mathbf{6}, \mathbf{7}, \mathbf{7 a}$ showed complex formation with DNA as observed by the presence of DNA in the wells. When the DNA was incubated with these complexes at $1 \mu \mathrm{g} /$ reaction mixture no effect was observed on the migration of DNA except for complex $1 a$ which showed DNA complex in the well.

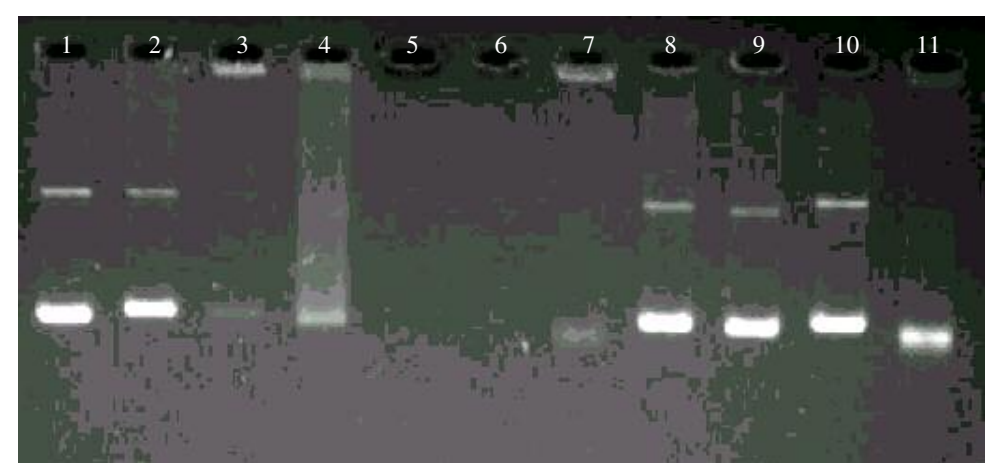

Figure S1. Gel mobility shift assay of complexes $(10 \mu \mathrm{g})$ without topoisomerase II. Lane 1: pBR322 DNA alone; Lane 2: 1; Lane 3: 2; Lane 4: 3; Lane 5: 1a; Lane 6: 2a; Lane 7: 3a; Lane 8: 3c; Lane 9: 3d; Lane 10: 4; Lane 11: 5. 


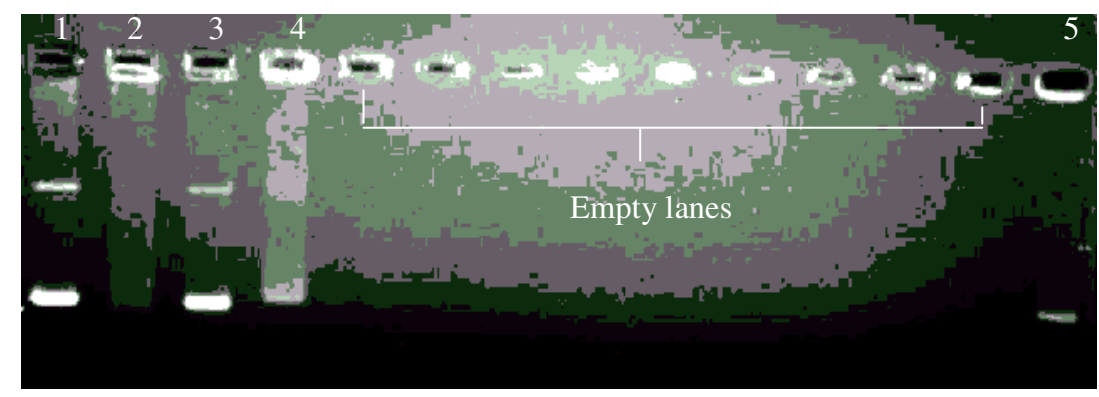

Figure S2. Gel mobility shift assay of complexes $(10 \mu \mathrm{g})$ without topoisomerase II. Lane 1: pBR322 DNA alone; Lane 2: 6; Lane 3: 5a; Lane 4: 7; Lane 5: $7 \boldsymbol{a}$.

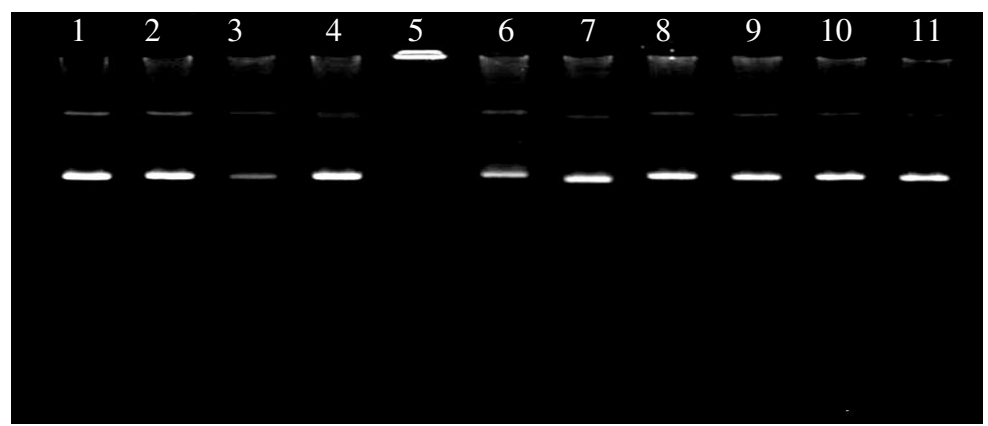

Figure S3. Gel mobility shift assay of complexes $(1 \mu \mathrm{g})$ without topoisomerase II. Lane 1: pBR322 DNA alone; Lane 2: 1; Lane 3: 2; Lane 4: 3; Lane 5: 1a; Lane 6: 2a; Lane 7: 3a; Lane 8: 3c; Lane 9: 3d; Lane 10: 4; Lane 11: 5.

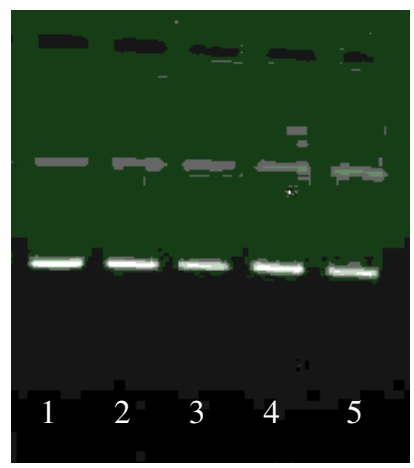

Figure S4. Gel mobility shift assay of complexes $(1 \mu \mathrm{g})$ without topoisomerase II. Lane 1: pBR322 DNA alone; Lane 2: 6; Lane 3: 5a; Lane 4: 7; Lane 5: $7 \boldsymbol{a}$. 


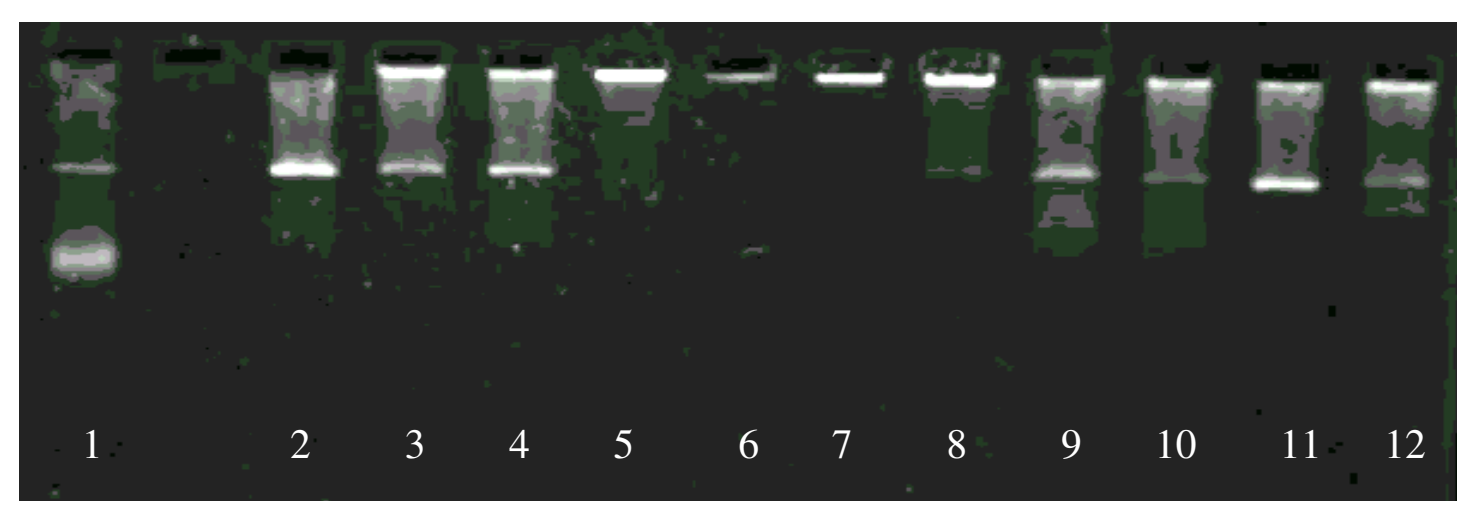

Figure S5. Gel mobility shift assay of complexes $(10 \mu \mathrm{g})$ with topoisomerase II. Lane 1: pBR322 DNA alone; Lane 2: pBR322 DNA + topo II; Lane 3: 1; Lane 4: 2; Lane 5: 3; Lane 6: 1a; Lane 7: 2a; Lane 8: 3a; Lane 9: 3c; Lane 10: 3d; Lane 11: 4; Lane 12: 5.

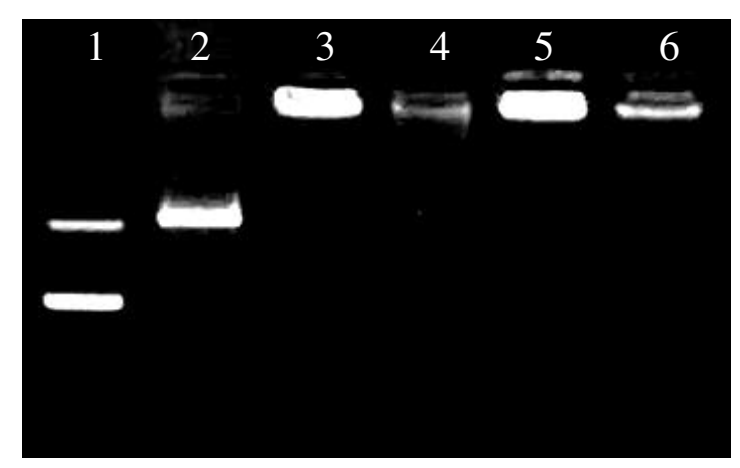

Figure S6. Gel mobility shift assay of complexes (10 $\mu \mathrm{g})$ with topoisomerase II. Lane 1: pBR322 DNA alone; Lane 2: pBR322 DNA + topo II; Lane 3: 6; Lane 4: 5a; Lane 5: 7; Lane 6: $7 a$.

The effect of these compounds on topoisomerase activity when tested at 40,10 and 1 $\mu \mathrm{g} /$ reaction mixture concentration (Figure S5-S6 and Main manuscript, Figure 4-7) showed that these complexes inhibited the DNA topoisomerase activity as measured by conversion of supercoiled DNA to relaxed form DNA significantly at $40 \mu \mathrm{g} /$ reaction mixture concentration. These compounds seem to inhibit the first step of the DNA topoisomerase reaction i.e. by inhibiting the binding of enzyme with the substrate and trapping the topo-DNA complex as mentioned in the original manuscript. Previously strong topo-inhibitory activity by arenecapped-ruthenium complexes has been demonstrated as measured by formation of cleavage complex or cross-linking with topoisomerase (Ref. 9). 